\title{
A evolução da segurança no trabalho aplicada na manutenção industrial 4.0
}

\author{
The evolution of safety work applied in the industrial maintenance 4.0
}

Recebido: 12/03/2020 - Aprovado: 01/06/2020 - Publicado:01/07/2020

Processo de Avaliação: Double Blind Review

Carlos Alberto de Freitas

carlos.afreitas@fatec.sp.gov.br

Fatec Osasco, Brasil

https://orcid.org/0000-0001-9137-6844

Adriano Real Silva

adrianostartengenharia@gmail.com

Fatec Osasco, Brasil

https://orcid.org/0000-0003-3577-3532

Diogo Silva de Aguiar

diogo.aguiar997@gmail.com

Fatec Osasco, Brasil

https://orcid.org/0000-0002-6838-9548

Marcio Manoel da Silva

marcio191b@gmail.com

Fatec Osasco, Brasil

https://orcid.org/0000-0003-0148-2067

Aline da Silva Cardoso

aline.cardoso@fatec.sp.gov.br

Fatec Osasco, Brasil

https://orcid.org/0000-0002-8283-2032

Deocleciano Reis Martins

deocleciano.rmartins@fatec.sp.gov.br

Fatec Osasco, Brasil

https://orcid.org/0000-0001-5576-6343

Antonio Carlos Santos de Arruda

antonio.arruda@fatec.sp.gov.br

Fatec Osasco, Brasil

https://orcid.org/0000-0002-5031-2825

REMIPE- Revista de Micro e Pequenas Empresas e Empreendedorismo da Fatec Osasco V. $6 \mathrm{~N}^{\circ} 2$ jul.-dez. 2020. 


\section{RESUMO}

Este estudo tem o objetivo de relacionar o surgimento da Indústria 4.0 e o impacto dessa revolução no contexto da segurança do trabalho dentro da manutenção industrial. Por meio de pesquisas, foi possível observar que os dois temas constituem uma conexão. A ideia principal da Indústria 4.0 é de facilitar e ampliar a comunicação entre máquinas, sistemas e ativos, possibilitando até um monitoramento remoto de equipamento, isso foi considerado um marco na indústria pelas inovações tecnológicas nos campos de automação, controle e tecnologia da informação. Com a chegada da Indústria 4.0, a manutenção de ativos passou a ter a possibilidade de antecipar a detecção de problemas, podendo ser chamada de manutenção prescritiva. Isso é possível devido às tecnologias aplicadas no processo e alinhadas com um bom Planejamento e Controle de Manutenção (PCM). Em relação à segurança do trabalho, os equipamentos só podem ser instalados ou modificados se atenderem os requisitos mínimos, conforme normas vigentes, com itens obrigatórios de segurança, interfaces de segurança de acordo com a NR 12 e NR10, no quesito de um dispositivo elétrico eletrônico.

Palavras-chave: indústria 4.0, manutenção industrial, segurança do trabalho, NRs.

\section{ABSTRACT}

This study aims to relate the emergence of Industry 4.0 and the impact of this revolution in the context of safety work within industrial maintenance. Through a research it was possible to observe that the following aspects constitute the connection of the themes. The main idea of Industry 4.0 is to facilitate and expand communication among machines, systems and assets, even allowing remote monitoring of equipment. This was considered a milestone in the industry by technological innovations in the fields of automation, control and information technology. With the arrival of Industry 4.0, asset maintenance, nowadays, has the possibility to anticipate the detection of problems, which can be called prescriptive maintenance. This is possible due to the technologies applied in the process and aligned with good Maintenance Planning and Control (MPC). In relation to safety work, the equipment can only be installed or modified if it meets the minimum requirements, according to current regulations, with mandatory safety 
REMIPE

items, safety interfaces in accordance with NR 12 and NR10, in terms of an electronic electrical device.

Keywords: industry 4.0, industrial maintenance, safety at work, NRs.

\section{INTRODUÇÃO}

Em termos globais, a Indústria 4.0 tem avançado rapidamente, mas por diversos aspectos alguns setores encontram dificuldades em adequar-se à algumas mudanças desse contexto. Devido à tecnologia, exigências de projeto, instalação, operação, entre outros, alguns países acabam enfrentando grandes problemas para aumentar seu poder tecnológico e se adequar às normas de segurança vigentes. A partir dessa condição, o trabalho realizado consiste em apresentar como as áreas de conhecimento se desenvolveram na indústria ao longo do tempo e qual o impacto dessa evolução no cenário nacional.

Qual a relevância da segurança do trabalho no setor de manutenção industrial, baseadas nas características da Indústria 4.0?

Com o avanço tecnológico se espalhando pelo mundo, é muito comum que o mercado exija resultados mais expressivos em termos de segurança, produtividade e qualidade. As empresas brasileiras, devido a diversos aspectos, podem demorar algum tempo para conseguir se adaptar por completo a essa tecnologia, porém, com a competitividade do mercado aumentando, é natural que as empresas busquem alternativas para atenderem a essa demanda.

As Normas Regulamentadoras estabelecem procedimentos para as empresas e profissionais. Esses procedimentos somados a algumas questões governamentais se tornam muito restritivos e podem gerar resistência por parte das empresas e, até mesmo, por parte de colaboradores, pois a cobrança pelos resultados é constante. Em um cenário mais tecnológico (com máquinas em operação remota, robôs colaborativos, etc.), um mantenedor, além de suas habilidades técnicas, deverá ter conhecimentos avançados em análise de dados, aprendizado de máquina e uso de ferramentas de manutenção remota, junto a esses conhecimentos deverá ter a 
segurança como um valor, apoiados aos profissionais da área de segurança do trabalho, que darão todo suporte necessário, antes, durante e depois da realização das atividades que possam oferecer risco. Para que haja essa conscientização entre os profissionais em relação à segurança do trabalho, todos os setores devem estar alinhados e com valores bem estabelecidos.

O objetivo deste trabalho está baseado em mostrar a evolução da indústria, manutenção e segurança do trabalho até o contexto da $4^{\text {a }}$ revolução industrial. De acordo com as características das áreas de conhecimentos apresentadas, podemos observar como as indústrias brasileiras estão abordando a segurança do trabalho no setor de manutenção, em torno do conceito de indústria 4.0, quais caminhos e procedimentos devem seguir para que possam ter resultados expressivos nesse quesito, onde a tecnologia se renova e a exigência com relação homem-máquina aumenta consideravelmente a cada dia.

\section{REFERENCIAL TEÓRICO}

No decorrer deste trabalho, é possível conhecer a evolução da indústria, passando por grandes transformações até a chegada da quarta revolução industrial, além dos impactos positivos, negativos e as consequências que esse contexto apresenta.

Na área de Manutenção Industrial, segundo Venturelli (2019), a digitalização apresenta soluções importantes como gerenciamento de ativos em rede (Cloud Computing), uso de realidade aumentada, criação de modelos de predição (Machine Learning), entre outros. Um dos aspectos da Indústria 4.0, é a criação de um modelo virtual das máquinas e de todo o sistema produtivo e, essa ideia pode ser complementada por um dos temas mais atuais em Manutenção Industrial: a Manutenção Prescritiva. Conforme Nascif e Kardec (2019), a capacidade analítica nas máquinas e sistemas permite que sejam capazes de não somente prever o que está por ocorrer, mas oferecer alternativas que possam modificar o resultado.

De acordo com Simonetti (2019), a segurança na Indústria 4.0 apresenta a importância da Norma Regulamentadora 12 (NR12) tanto na adequação quanto na instalação de máquinas e equipamentos. Os trabalhadores envolvidos na operação, manutenção, inspeção e demais intervenções em máquinas e equipamentos devem receber capacitação providenciada pelo 
empregador e compatível com suas funções, que aborde os riscos a que estão expostos e as medidas de proteção existentes e necessárias, nos termos dessa NR, para a prevenção de acidentes e doenças.

\subsection{As Quatro Fases da Revolução Industrial}

A partir de seu surgimento, a indústria vem sofrendo diversas mudanças com o passar dos anos. Desde a segunda metade do século XVIII até os dias atuais, a indústria tem passado por grandes modificações, cada uma delas denominada por uma numeração, para situar respectivos progressos. De acordo com a ocorrência dos fatos, a primeira Revolução Industrial, conhecida também como Indústria 1.0, é marcada pela criação das máquinas a vapor e início do êxodo rural. Na sequência, transcorreu a segunda Revolução Industrial trivialmente chamada de Indústria 2.0, onde decorreu a criação de motores a combustão e a instauração da eletricidade. Na Indústria 3.0, destaca-se a Revolução Técnico-Científico-Informacional, pois com grandes avanços no campo da ciência, foi possível desenvolver grandes tecnologias que tornaram possível o aperfeiçoamento da indústria, em conjunto a isso, a expansão da comunicação entre os países. A Quarta Revolução Industrial, Indústria 4.0, elevou o conceito de tecnologia, usando de métodos como Internet das Coisas (IoT), e a nuvem (Cloud), meio utilizado para armazenamento de dados sem que exista a preocupação de perda de dados, sendo utilizados para processos de produção e monitoramento de manutenção.

\subsubsection{Primeira Revolução Industrial (Indústria 1.0)}

Até o século XVIII, todo o trabalho era realizado de maneira artesanal, ou seja, os trabalhos eram feitos de maneira braçal. Até então, a produção era feita de acordo com os produtores do campo, onde eles produziam para o próprio consumo. Na Europa, países como a França e a Inglaterra tinham indústrias que funcionavam com 100\% do trabalho realizado de maneira braçal.

De acordo com Boetcher (2015), entre os séculos XVIII e XIX, a Inglaterra iniciou um movimento para que fosse possível mudar o modo que as indústrias produzissem, fazendo com que a produção aumentasse e, consequentemente, melhorasse a economia do país, portanto, houve na Revolução Industrial a mudança do trabalho braçal para o maquinário, que ocasionou o início do êxodo rural. 
Conforme Boetcher (2015), junto às máquinas efetuou-se o avanço no transporte. Através da ciência, foi descoberto que a queima do carvão tem um potencial energético muito eficiente na geração do vapor, o que proporcionou a criação das máquinas movidas a vapor e as locomotivas. Os primeiros setores a adotarem a inovação, foi o setor têxtil, em sequência, outros setores partilharam da mesma ideia. No mesmo sentido de crescimento, as locomotivas entram para auxiliar na distribuição do que se produzia, possibilitando um alcance maior em um menor tempo, aumentando assim a economia dos países que aderiram à revolução.

Em contrapartida, Neves e Sousa (2020) mencionam que ocorreu uma diminuição no quadro dos funcionários, que passaram a trabalhar com uma carga de 16 horas por dia, com pausa de trinta minutos para almoçar e recebiam salários bem menores do que quando realizavam todo o trabalho braçal. Sem nenhum tipo de segurança para trabalhar, os operários se sujeitavam a essa rotina e muitos acidentes aconteciam. O mais comum dos acidentes era quando os operários prendiam seus dedos nas máquinas e, assim, muitos os perdiam. Se o operário fosse afastado devido a problemas de saúde, não havia nenhum benefício, também poderiam ser demitidos devido ao afastamento, ou seja, somente os que trabalhavam recebiam.

Essa situação que a tantos incomodava gerou uma grande agitação na classe operária, fazendo com que surgissem as organizações dos trabalhadores (na Inglaterra com o nome de Trade Union e, no Brasil, conhecido como Sindicatos), que lutavam por condições melhores, como menor carga horária e uma digna remuneração (SOGGI, 2019).

\subsubsection{Segunda Revolução Industrial (Indústria 2.0)}

Com o crescimento das indústrias e suas máquinas a vapor, os meios de transportes foram avançando. De acordo com as mudanças que a revolução trouxe, a esperança que se tinha na época era de que esse movimento só tendia a aumentar ainda mais. Em reflexo ao crescimento da indústria, foram criados também transportes marítimos que se moviam a vapor, o que pôde possibilitar a interligação entre os continentes (BOETCHER, 2015).

A Segunda Revolução Industrial é caracterizada pela expansão da indústria pelos continentes, chegando a grandes potências como, por exemplo, os EUA (Estados Unidos da América), França e Alemanha. Os principais recursos dessa segunda fase eram a produção do aço, a eletricidade e o petróleo. 
Segundo Soggi (2019), durante a transição da primeira para segunda fase, é possível afirmar que diante do ocorrido com os trabalhadores e seus pedidos para condições melhores de trabalho, por volta do início do século XIX, alguns países começaram a ditar regulamentos que protegessem seus proletariados. Outros países, como os EUA, começaram a movimentar regulamentos do tipo, porém só houve uma normatização das regras a partir do século seguinte.

No início do século XX, especificamente no ano de 1919, surgiu a Organização Internacional do Trabalho (OIT). A OIT nasceu com o intuito de formular e aplicar as normas de trabalho por meio de convenções e recomendações ao mundo todo.

\subsubsection{Terceira Revolução Industrial (Indústria 3.0)}

A terceira fase da Revolução Industrial é caracterizada por se passar em um período pós-guerra. Após a Segunda Guerra Mundial, muitos avanços tecnológicos e informativos aconteceram, daí é possível afirmar que a Terceira Revolução Industrial se denomina por ser a Revolução Técnico-Científico-Informacional (BRASIL ESCOLA, 2020).

Se na primeira fase da revolução a fonte principal de energia era a queima do carvão para gerar o vapor e, na segunda surgiu a eletricidade e o petróleo como fontes de energia, a terceira fase apresenta outros meios de energia e algumas delas sendo renováveis, como por exemplo, a energia eólica, um método que utiliza do vento para a movimentação de grandes pás, que são utilizadas para gerar energia mecânica e transformá-la energia elétrica.

Muitos acontecimentos marcaram esse período, tais como, a circulação da informação através da internet, possibilitando a comunicação entre os países de maneira muito mais rápida e eficaz. Em conjunto a isso, foi criado também um modo de produção chamado Toyotismo.

O Toyotismo apresenta a ideia de que ao invés de produzir mais para vender, a produção acontece de acordo com a demanda pedida, conhecida como Just in Time, o que se chama de lei da oferta e procura. Com isso, era possível produzir para lucrar com menos funcionários.

O setor terciário se tornou uma característica da terceira fase da Revolução Industrial, pois se trata de uma classe de prestadores de serviços, autônomos entre outros, onde em consequência disso, a produção manual nas empresas caiu consideravelmente, fazendo com que 
não existissem mais profissionais em um único cargo. Com a diminuição do quadro de funcionários e aumento da tecnologia nas empresas para realização do serviço, os profissionais contratados tinham a necessidade de realizar multitarefas.

Vale ressaltar que a Terceira Revolução Industrial não aconteceu para todos, aconteceu apenas para países desenvolvidos e alguns outros países que implantaram as multinacionais. Muitos países ainda não chegaram à Terceira Tevolução Industrial e ainda possuem métodos arcaicos de produção.

A terceira fase da revolução trouxe para o mundo muitos avanços tecnológicos que impactaram diretamente nos métodos de produção. A automação de processos produtivos trouxe uma maior capacidade de controle de qualidade do processo e tornou possível o aumento da produção, junto com a robótica e com a utilização de softwares para controle.

Muitas mudanças com relação à segurança aconteceram desde a segunda fase até a terceira, de modo em que as empresas tivessem mais consciência com seus colaboradores e com o meio ambiente, muita inovação foi atribuída pensando no bem-estar do colaborador e na segurança que o empregado necessitava.

\subsubsection{Indústria 4.0}

Conforme Fia (2018), após a terceira fase da revolução, muitos avanços foram dados dentro da tecnologia, inclusive, no que se trata de avanço no campo da informação. Com o desenvolvimento tecnológico sempre em alta e a internet sempre caminhando a favor da evolução, foi possibilitada uma gama muito alta no que se trata de inovação. No ano de 2011, a Alemanha usou o termo "Indústria 4.0" pela primeira vez, onde os alemães focaram seus estudos em tecnologia para o aperfeiçoamento dos seus processos industriais.

A ideia principal da Indústria 4.0 é a de facilitar e ampliar a comunicação entre máquinas, sistemas e ativos, possibilitando até um monitoramento remoto de equipamentos. Mas para se entender como funciona, é recomendado que se aprenda sobre IoT (Internet of Things/ Internet das Coisas) e sobre Big Data. O IoT, basicamente, é a tecnologia responsável por fazer a comunicação entre máquinas, equipamentos eletrônicos que são responsáveis por monitorar ou até mesmo realizar comandos dos maquinários, e o melhor de tudo é que todas 
essas ações podem ser feitas de maneira remota. Tendo em vista que todo o armazenamento de dados é feito em nuvem, o sistema não compromete a troca de informações entre equipamentos. Já o Big Data é responsável pela quantidade enorme de informações que a internet possui, tendo em vista que é responsável pela junção e organização dos dados diretamente na rede. Sua funcionalidade se estende também para a permissão de dados que fazem com que as máquinas possam trabalhar de maneira mais eficiente.

Quando se menciona o conceito de Indústria 4.0 é pensado nas várias possibilidades em que ela pode melhorar no setor industrial, por exemplo, na segurança do trabalho os métodos para a prevenção contra acidentes e também a saúde ocupacional pode ser vista através de sensores e monitoramento de linhas de trabalho, de maneira que os colaboradores não se sujeitem a condições precárias de trabalho, e nem situações que comprometam sua saúde futura, como por exemplo, Lesões por Esforços Repetitivos (LER) e Distúrbios Osteomusculares Relacionados ao Trabalho (DORT).

\subsection{Manutenção Industrial}

A Manutenção Industrial evoluiu conforme a área técnico-industrial se desenvolvia e tinha como principal combustível as mudanças no perfil de mercado. No início do século XX, em meados de 1914, a manutenção tinha pouca importância, era considerada como secundária no processo produtivo, as indústrias da época não tinham equipes especializadas em manutenção e as indústrias trabalhavam obtendo a máxima produção das máquinas até que estas avariassem ou parassem definitivamente (MARTINS, 2019).

Com a implantação do sistema de produção em série, de Henry Ford, as fábricas passaram a estabelecer programas mínimos de produção e, em consequência disso, sentiram necessidade de criar equipes que pudessem efetuar reparos em máquinas operatrizes no menor tempo possível. Assim, surgiram os primeiros mantenedores de ofício, cujo objetivo básico era de execução da manutenção corretiva, nessa época o órgão de manutenção era subordinado da operação. A manutenção ganhou um papel de destaque após a passagem da Segunda Guerra Mundial, com o surgimento da manutenção preventiva, uma técnica que tinha como princípio evitar as falhas e não apenas corrigi-las. 
Após a década de 50, surgiu uma grande evolução na aviação comercial e na indústria eletrônica. Com as preventivas baseadas no tempo ou horas trabalhadas, observou-se que o tempo gasto para diagnosticar as falhas era maior do que o de execução do reparo. Devido essa questão, a alta administração decidiu selecionar equipes de especialistas, a fim de compor um órgão de suporte, chamado Engenharia de Manutenção, com intuito de planejar e controlar a manutenção preventiva e analisar as causas e efeitos das falhas.

Com a expansão dos computadores e o fortalecimento das Associações Nacionais de Manutenção, a Engenharia de Manutenção passou a desenvolver critérios mais sofisticados de manutenção baseada em condições, esses foram unidos a sistemas automatizados de planejamento e controle, reduzindo os serviços burocráticos dos mantenedores (CORTIZO, 2017).

Com a chegada da Indústria 4.0, a manutenção de ativos passou ter a possibilidade de antecipar a detecção de problemas, podendo ser chamada de manutenção prescritiva, isso é possível devido às tecnologias aplicadas no processo e alinhadas com um bom Planejamento e Controle de Manutenção (PCM).

\subsubsection{Planejamento e Controle de Manutenção - PCM}

O setor de PCM - Planejamento e Controle de Manutenção é responsável por traçar estratégias de manutenção que sejam capazes de garantir a confiabilidade e disponibilidade dos ativos. Além de manter essa disponibilidade e confiabilidade, o PCM também deve manter a produtividade da equipe de manutenção.

O PCM é um setor que está há mais de 70 anos atuando e, desde então, não tem passado por atualizações significativas. O maior marco referente à atualização do setor foi a informatização, que aconteceu há cerca de 40 anos. Antes, tudo era feito e controlado manualmente, com uso de papel e caneta. Com a informatização, foram introduzidos softwares para gestão da manutenção e esses softwares automatizaram algumas ações, evitando a ocorrência de falhas humanas na gestão e controladoria da manutenção. 
O conceito antigo de produtividade prega: Fazer mais, com menos. Ou seja, realizar cada vez mais atividades de manutenção com menos recursos (menos tempo, pessoas, peças de reposição e consequentemente, menos dinheiro).

O novo conceito de produtividade na manutenção prega: Fazer menos, com menos. Ou seja, realizar cada vez menos atividades de manutenção, com recursos cada vez mais reduzidos.

O PCM deve se adequar a esse novo conceito, caso tenha interesse em se manter um setor competitivo, estratégico e alinhado com os objetivos globais. Agora, estamos na Quarta Revolução Industrial, e junto à ela temos a nova geração da manutenção, que visa trazer uma infinidade de novos conceitos para suportar essa nova fase da indústria (TELES 2017).

\subsubsection{Aspectos da Manutenção 4.0 (Manutenção Prescritiva)}

Com a chegada da Indústria 4.0, surge à análise prescritiva que estabelece a Manutenção Prescritiva, essa capacidade analítica nas máquinas e sistemas é capaz de não somente prever o que está por ocorrer, mas oferecer alternativas que possam prever o resultado. Para isso acontecer há que se ter, podemos assim dizer, um pacote de tecnologias onde estão presentes a Internet das Coisas na Indústria, um grande conjunto de dados (Big Data), e através de algoritmos, indicar ou recomendar as ações/ atividades de manutenção (ou de operação), prescrevendo o que pode dar melhor resultado (NASCIF; KARDEC, 2019, p. 85).

Um dos aspectos da Indústria 4.0 é a criação de um modelo virtual das máquinas e de todo o sistema produtivo, de forma que esse possa ser controlado e operado remotamente. Essa prática é facilitada pela instalação de sensores que enviam aos softwares de comando a situação atual de cada equipamento. Esse sistema possibilita a detecção de falhas no processo e irregularidades no desempenho dos equipamentos de forma instantânea.

Na prática, o sensoriamento das peças pode ser capaz de mostrar as falhas iminentes, sendo o operador capaz de resolvê-las antes que o equipamento possa ter uma falha funcional ou coloque a segurança de uma pessoa em risco. Em alguns casos, as falhas podem ser corrigidas até mesmo sem a necessidade de ação humana. 
Um exemplo de aplicação de alguns dos conceitos citados é o Sistema Smart, apresentado pela empresa Welle Laser, conforme caso abaixo.

O Sistema Smart implantado pela Welle Laser na sua máquina de corte CS 3000 traz consigo estes conceitos da indústria 4.0. O monitoramento do sistema é hoje realizado por diversos sensores que indicam o desempenho de cada um dos subsistemas da máquina. Estes dados são disponibilizados online para um operador remoto que pode controlar e inclusive monitorar por meio de câmeras o desempenho da máquina. Além disso, o sistema de alimentação com duas mesas de troca permite agilidade na troca de chapas e consequente aumento da produtividade (BONIFACIO 2017).

\subsubsection{A Digitalização na Manutenção 4.0}

A manutenção tem um papel fundamental dentro da cadeia de valores da indústria, que é manter a disponibilidade produtiva e permitir o uso dos ativos em todo o seu ciclo de vida, no menor custo operacional.

De acordo com Venturelli (2019), a digitalização é um processo que está provocando uma grande mudança na forma de executar a manutenção na indústria. Atualmente, a manutenção tem seus indicadores mostrados a partir de eventos que aconteceram e estão acontecendo. Com as tecnologias da Indústria 4.0 implantadas, é adicionado o elemento futuro na manutenção, passando a responder o que irá acontecer, aplicando uma camada de Internet das Coisas na gestão dos ativos e usando Inteligência Artificial apoiando o técnico de manutenção na tomada de decisões futuras.

Os sistemas vão se desenvolvendo de acordo com que os ativos da planta vão gerando dados, esses dados são enviados para camadas de Computação em Nuvem, onde nessa, é utilizado algoritmos de predição, que podem ser baseados em mineração de dados e/ou aprendizado de máquina.

O sistema se torna mais eficiente, porque ao utilizar o monitoramento de tempo real, promovido pela camada de IoT, associado ao uso de A.I (Artificial Intelligence / Inteligência Artificial), permite diminuir o tempo de tomada de decisões, aumentando a disponibilidade de equipamentos da planta.

A seguir, as principais soluções de Digitalização que constituem a Manutenção 4.0:

REMIPE- Revista de Micro e Pequenas Empresas e Empreendedorismo da Fatec Osasco V. $6 \mathrm{~N}^{\circ} 2$ jul.-dez. 2020. 
- Ações de manutenção baseada em Eventos;

- Gerenciamento de Ativos em rede e Cloud Computing;

- Uso de Realidade Aumentada;

- Criação de Modelos de Predição (Machine Learning);

- Eliminar Manutenção Preventiva;

- Conectar Inventário de Fábrica;

- Monitorar Técnico de Manutenção (Segurança);

- Uso de acesso Remoto (Drone e VPN).

Com base nas soluções citadas anteriormente, podemos observar como esse novo cenário utiliza a tecnologia a seu favor, podendo elevar a produtividade e a segurança ao mesmo patamar. Com todas essas mudanças acontecendo, será necessário que os profissionais da manutenção adquiram novos conhecimentos e habilidades para lidar com a Digitalização na indústria 4.0, por exemplo, aprender análise e aquisição de dados (IoT e Data Science), criar modelos para aprendizado de máquina (Machine Learning) e usar ferramentas de manutenção remota.

De acordo com as soluções apresentadas pela digitalização, pode-se destacar duas, como as mais relevantes no impacto à segurança do profissional de manutenção na Indústria 4.0, são elas:

a) Monitorar Técnico de Manutenção (Segurança):

- Usar sensores de geoposicionamento na equipe de manutenção para análise de permissões;

- Usar sensores de gases nos técnicos e monitoramento de sinais vitais na camada de IoT, relacionando operação e segurança;

- Conectar ações de segurança operacional com os técnicos, tudo na rede, analisando permissões, contingência e cenário de trabalho.

b) Uso de acesso Remoto (Drones):

- Utilizar Drones em inspeções de difícil acesso e com problemas de segurança em plantas; 
- Drones para fazer mapeamento e planejamento de prioridades de manutenção em estruturas e vasos de pressão;

- Análise de perímetro para segurança de acesso e movimentação crítica (Ciber Segurança).

\subsection{A SAÚDE E SEGURANÇA NO TRABALHO E SUAS NORMAS}

A Saúde, Segurança e Medicina do Trabalho propõem uma reflexão sobre a efetividade da garantia constitucional de redução dos riscos inerentes ao trabalho. Nos dias atuais, são referenciadas por Normas Regulamentadoras, as chamadas NRs, decretos e portarias que são utilizados como base para o trabalho e o exercício das atividades profissionais amparadas por legislações específicas e contempladas nos direitos sociais constitucionais, disseminadas tanto no cenário empresarial quanto na fiscalização por funcionários da administração pública. $\mathrm{O}$ Ministério do Trabalho e Emprego (MTE) pode interditar qualquer empresa que não seguir os requisitos mínimos legais relacionados às máquinas e/ou processos, aplicando multas e sanções além de embargar qualquer atividade que ofereçam risco ou uma condição eminente de acidente para com os trabalhadores.

A Associação Brasileira de Normas Técnicas (ABNT) é uma instituição, que contribui para a implementação de políticas públicas, promoção do desenvolvimento e melhoria contínua na saúde e segurança de todos os colaboradores brasileiros, seu surgimento ocorreu a partir do aumento dos índices dos acidentes de trabalho por vários e determinados setores industriais brasileiros. A ABNT é o órgão responsável pela normalização técnica no Brasil e fornece ainda diversos insumos ao desenvolvimento tecnológico brasileiro. Tratando-se de uma entidade privada e sem fins lucrativos e de utilidade pública, fundada em 1940, a ABNT, também é membro fundador da International Organization for Standardization (ISO - Organização Internacional de Normalização), da Comisión Panamericana de Normas Técnicas (COPANT Comissão Pan-Americana de Normas Técnicas), da Asociación Mercosul de Normalización (AMN - Associação Mercosul de Normalização) e da International Electrotechnical Commission (IEC- Comissão Eletrotécnica Internacional).

No Brasil, em meados de 1943, a Consolidação das Leis Trabalhistas (CLT) foi o órgão criado com o intuito de ser o instrumento jurídico para organizar e adotar medidas que 
estabelecessem requisitos mínimos ao trabalhador. Em 1978, foram criadas 28 Normas Regulamentadoras, havendo uma grande evolução na segurança, onde reduziram a exposição às atividades inseguras e minimizaram os riscos e acidentes preservando a saúde e a integridade física do trabalhador, desenvolvendo procedimentos e requisitos mínimos para a execução das tarefas de risco.

Segundo o Instituto Brasileiro de Ensino Profissionalizante (2017), os procedimentos de segurança que antes eram adotados para atendimento de meras formalidades legais, agora passaram a fazer parte da gestão das empresas. Podem-se destacar algumas medidas importantes com o objetivo de contribuir com as atividades laborais nos mais diversos ambientes de forma segura, por exemplo, a adaptação do trabalho ao homem, em relação à ergonomia; a consolidação do novo conceito de saúde, onde é abordada a saúde física, mental e social; os trabalhadores passam a ter acesso às informações relativas à segurança e à saúde no ambiente de trabalho, entre outras.

É muito comum para as empresas e, muitas vezes, até obrigatória, a manutenção de uma equipe de profissionais para atuar na segurança do trabalho de forma direta ou indireta. No Brasil, ela se desdobra nas atividades das Comissões Internas de Prevenção de Acidentes (CIPA) e no Serviço Especializado em Segurança e Medicina do Trabalho (SESMT), para que assim possa garantir que os requisitos legais que são exigidos estejam sendo seguidos, visando também a redução ou eliminação dos riscos na execução das tarefas laborais para prevenção de acidentes, promoção da saúde, elaborando documentos que regularizem a empresa perante os requisitos mínimos exigidos reduzindo assim, o prejuízo às empresas e instituições previdenciárias.

Segundo a Confederação Nacional da Indústria (2017), o mundo do trabalho tem passado por mudanças relevantes nos últimos anos. Essa transformação, que teve início na primeira revolução industrial, avançou em passos largos lado a lado com a revolução tecnológica e a globalização. Essa inovação exigiu novas formas de produzir e trabalhar, o que, em consequência, levou a modificações no perfil das profissões nos últimos anos. Tamanha revolução implica em desafios constantes, não só nos tipos de emprego, mas também nas relações entre empregador e trabalhador que têm se reinventado e precisarão se reinventar ainda mais neste contexto. 
Com a chegada da Indústria 4.0, as NRs foram modificadas através de uma comissão tripartite composta por representantes do governo, empregadores e empregados, e, algumas sofreram alterações por meio de Portarias expedidas pelo MTE, para atenderem as novas mudanças perante as implementações de novas tecnologias que se enquadrarem nas indústrias. Isso se refere principalmente as empresas automobilísticas, as de grande porte e as de produção contínua.

Nesse novo paradigma industrial, há o esforço para que ocorra a automatização total dos processos de produção, o que é possível em razão de ferramentas como a computação em nuvem e a internet das coisas, as quais são essenciais, no quesito segurança do trabalho na Indústria 4.0, as empresas, ao se adequarem, realizarão um planejamento prevendo que diversas profissões serão extintas e muitas outras surgirão em relação ao trabalho, com a unificação dessas tecnologias. As exigências, de acordo as normas, os equipamentos, quando tiverem as modificações solicitadas realizadas, poderão ser utilizados se atenderem os requisitos mínimos de segurança conforme normas vigentes, dispositivos de segurança, tais como cortinas de luz, sistemas de segurança com botão de emergência, chaves de emergência, chaves de fim-decurso, chaves de segurança com travamento e bloqueio, chaves de segurança magnética, sensores indutivos de segurança, sensores de segurança com Identificação por Rádio Frequência (RFID - Radio Frequency Identification), detectores de presença com optoeletrônicas, interfaces de segurança e manobra conforme a NR 12. E direcionado à área eletroeletrônica, a evolução também se dará por parte dos equipamentos, onde um deles é o lockout/tagout, um dispositivo de segurança de intertravamento da eletricidade, além de outros que atenderem a NR 10.

O profissional de segurança do trabalho deverá ir além das exigências legais atuando como um verdadeiro gestor, além disso, um novo perfil de funcionários surgirá e exigirá multiplicidade de habilidades e mais dedicação à tecnologia usada a favor dos próprios profissionais, além da adoção de ferramentas para monitoramento de indicadores, cumprimento das ações e softwares para copilar e analisar os dados. Isso também proporcionará ganhos como flexibilidade e rapidez na entrega do produto final, padronização de procedimentos e de mais segurança nos processos. 
Os avanços tecnológicos afetam as diversas áreas de conhecimento. Pois, os trabalhadores e profissionais da área de saúde e segurança do trabalho no Brasil, perante as novas exigências e solicitações de modernização para atendimento de novas demandas das empresas e do governo, muitas vezes não acompanham essa evolução. Um exemplo de soluções proporcionadas pelas tecnologias da Indústria 4.0 voltadas para a saúde e segurança do trabalhador, foi a criação de um programa desenvolvido pelo governo Federal, o E - Social, que é um Sistema de Escrituração Fiscal Digital das Obrigações Fiscais Previdenciárias e Trabalhistas, ele foi aprovado através do decreto 8.373, de 11 de dezembro de 2014. Trata-se de uma ferramenta para consolidar as obrigações acessórias da área trabalhista de uma empresa em uma única entrega. O Governo Federal tornou esse sistema obrigatório para todas as empresas do país passando a valer a partir de $1^{\circ}$ de julho de 2018 . E mesmo com essa nova tecnologia, o governo não conseguiu manter o mérito de estar codificando todos os dados de empresas no qual estão cadastrados em sua base de dados. E devido ao sistema não ter sido implementado de acordo com o que o governo promoveu e as empresas não terem se enquadrado, ele será extinto conforme Globo (2019).

Segundo a Smartlab (2019), para as empresas que não se enquadram nas regulamentações de segurança, existe um estudo que eleva as discussões a uma suposta desburocratização dos Estados, essa intenção de desregulamentação e flexibilização das normas vigentes devem ser observadas com atenção, especialmente diante dos graves números que colocam o Brasil em quarto lugar no ranking mundial de maior ocorrência de acidentes de trabalho, denotando assim a urgência no que se refere à criação e melhoria de políticas públicas relacionadas à segurança laboral e conceito para implementação da Indústria 4.0. Essas medidas podem diminuir a exposição do homem ao risco no trabalho, pois ele será monitorado a todo momento através de softwares e tecnologias avançadas de automatização. Com o uso de robótica avançada em tarefas mais arriscadas, haverá menor exposição de risco do trabalhador, uma melhora na ergonomia e, consequentemente, aumento da segurança no trabalho.

Segundo a Confederação Nacional da Indústria (2017), com a Indústria 4.0, grande parte do trabalho, como por exemplo, as ocupações de serviços braçais acabarão sendo executadas por robôs e os trabalhadores deverão executar outras funções que exijam habilidades principalmente cognitivas, criativas e interativas. Estas características, conjuntamente com a nova dinâmica de trabalho, duração, condição e distribuição de tarefas, devem aumentar a 
sobrecarga mental. O desafio é, portanto, adaptar a segurança e medicina do trabalho a essa nova tendência e à transição demográfica. Para isso, algumas medidas que podem mitigar essas novas questões são:

- expansão do escopo da segurança no trabalho para regulamentar sobrecarga mental até o ano de 2018;

- desenvolvimento de estratégias de inovação, pesquisa e transferência de conhecimento referente à segurança no trabalho 4.0 para troca de boas práticas, incluindo:

- adaptação dos conceitos de segurança às novas tecnologias, como a interação homem e robô;

- aconselhamento e suporte aos trabalhadores em regimes flexíveis de trabalho;

- concepção preventiva do trabalho por meio da cooperação estreita com departamentos de pesquisa;

- formação e capacitação de funcionários e seus gestores para melhor prepará-los frente ao conceito de responsabilidade pela própria saúde;

- preparação de supervisores em relação a uma vasta gama de novos temas (por exemplo, o estresse psicológico), bem como, maior ênfase nas orientações sobre controle e penalizações;

- $\quad$ promoção da cultura de prevenção sustentável no ambiente de trabalho.

\section{METODOLOGIA}

Partindo de uma natureza básica, o presente trabalho foi desenvolvido com o objetivo exploratório, a fim de apresentar como as indústrias brasileiras estão posicionadas no conceito 4.0, e em particular, como o setor de manutenção industrial tem trabalhado a questão da segurança nesse contexto. Foram abordados de maneira qualitativa aspectos de como a evolução industrial, a evolução da manutenção e a evolução da segurança do trabalho estão relacionadas nesse panorama. Através de pesquisa-ação, foram utilizadas técnicas de pesquisas consagradas para propor algumas ações sobre o tema. A partir do estudo realizado, abriu-se espaço para a coleta de dados, que foi feita através de triangulação, pois além de pesquisas em literatura, foram coletadas informações, por meio de depoimentos de profissionais que atuam 
com conceitos que se relacionam à Indústria 4.0. Utilizamos o método fenomenológico para esclarecer e mostrar o que foi visto em literatura, somada às informações de vivência de alguns profissionais. Para analisar os dados obtidos utilizamos o critério de encadeamento lógico das evidências, que permite o acompanhamento claro e objetivo da pesquisa, a fim de mostrar com clareza como as etapas se desenvolveram para a conclusão da ideia.

\section{RESULTADOS E DISCUSSÃO}

A importância do estudo é mostrar como o setor de manutenção industrial está abordando a segurança do trabalho no contexto da Indústria 4.0. Por esse motivo, os principais aspectos desta pesquisa foram apresentar como as áreas de conhecimento evoluíram ao longo do tempo até a $4^{\mathrm{a}}$ Revolução Industrial, além de mostrar como as normas brasileiras estão se adequando para atender à essa demanda.

As empresas brasileiras encaram uma realidade muito difícil em relação à atualização de tecnologias e adaptação às Normas Regulamentadoras, que, por sua vez, podem ser muito restritivas, gerando resistência às mudanças propostas.

A empresa "X" está no cenário global há mais de 100 anos e é líder mundial na sua área e atuação, o gestor " $\mathrm{A}$ " faz parte de um grupo de colaboradores que contribuíram com a implantação de um novo setor na empresa, setor esse que aplica os conceitos da Indústria 4.0. De acordo com o Gestor "A", a adequação do ambiente e dos ativos em relação à NR12 (Proteção de Máquinas e Equipamentos) e NR10 (Instalações Elétricas) são um dos aspectos mais relevantes dentro desse novo cenário, além da efetivação do Bloqueio e Sinalização de Energias Perigosas (lockout e tagout), que tem o objetivo de conscientizar trabalhadores com respeito à sistematização da segurança e reduzir expressivamente riscos de acidente com traumas de extremidades e morte, durante tarefas como manutenção, setup e limpeza operativa.

Especialista em Indústria 4.0 e segurança do trabalho, o profissional "B" informa que no Brasil temos as normas de segurança do trabalho a serem cumpridas, como a NR12 e NR10 (mencionadas anteriormente). Mesmo em um cenário com os robôs colaborativos, os mesmos 
atendem as normas TS 15066, ISO 10218 e NBR 12100 que também os classificam em níveis de segurança como:

- N1 - Barreira de Segurança

- $\quad \mathrm{N} 2$ - Scanner

- N3 - Programação manual

- $\quad \mathrm{N} 4$ - Limite de força

Ainda segundo as informações do profissional "B", um robô colaborativo também precisa de um laudo de instalação que atenda a NR-12 para poder operar, fazendo com que a intervenção humana seja segura, pois apesar de não serem providos de força (suporta aproximadamente $10 \mathrm{~kg}$ ), eles possuem alta velocidade, e dependendo da ferramenta que possuir, pode perfurar facilmente o corpo humano.

O robô não precisa ser enclausurado, mas tem que possuir em sua programação o recurso de diminuição de velocidade e até de parada na presença humana (scanner) e, em alguns casos, o bloqueio imediato (barreira). Em um cenário com restrição de espaço em linhas de produção, os mesmos devem estar programados de forma a reduzir o ritmo do ciclo automaticamente durante a intervenção humana ao invés da interrupção total.

O setor de Engenharia de Manutenção deve inserir em seus planos de inspeção e procedimentos, um check-list de Segurança do Trabalho ou até mesmo se necessário uma autorização de trabalhos especiais (utilizado em trabalhos com eletricidade, altura, espaço confinado, entre outros) a fim de conscientizar o profissional que irá fazer uma intervenção, sobre os riscos que podem estar presentes na tarefa que será realizada, além do acompanhamento do profissional de segurança do trabalho que dará todo o suporte necessário.

Portanto, os profissionais inseridos no contexto da Indústria 4.0 serão cada vez mais autônomos e, por isso, treinamentos em novas tecnologias e segurança do trabalho serão cada vez mais exigidos pelas empresas, e também é importante a comunicação entre escolas e universidades sobre as tecnologias exigidas nas empresas, para o estudante ter condições de sair da sala de aula e carregar consigo conceitos básicos para atender às novas demandas do mercado. 


\section{CONSIDERAÇÕES FINAIS}

Concluímos que o profissional da manutenção terá que estar preparado e qualificado para atender à demanda quando o Brasil, como um todo, se adaptar à Indústria 4.0, sendo o conhecimento relacionado às novas tecnologias atreladas à preocupação com a segurança no ambiente de trabalho, o grande diferencial desse profissional.

O impacto da segurança do trabalho com relação à manutenção de ativos é muito grande. Muitas medidas são tomadas para proteção do efetivo operacional, porém, o mantenedor necessita em grande parte, ter acesso às partes internas dos equipamentos, à NR10, NR12 e às Normas que atendam os robôs colaborativos contribuem para minimizarem os riscos de acidentes. Mesmo seguindo orientações, procedimentos e respeitando as Normas Regulamentadoras, é fundamental que os setores estejam alinhados com relação à segurança e estejam determinados a trabalharem juntos para tornar o ambiente seguro.

Quando tratamos de segurança, erros não são aceitáveis e, somente as pessoas trabalhando juntas, com determinação e consciência podem tornar um ambiente adequado, com total segurança. Isso só poderá ser alcançado quando a segurança deixar de ser prioridade para algumas pessoas e se tornar um valor para todos.

\section{REFERÊNCIAS}

BOETTCHER, Maicon. Revolução Industrial - Um pouco de história da Indústria 1.0 até a Indústria 4.0, 2015. Disponível em: $<$ https://www.linkedin.com/pulse/revolu\%C3\%A7\%C3\%A3o-industrial-um-pouco-dehist\%C3\%B3ria-da-10-at\%C3\%A9-boettcher>. Acesso em 14 mai. 2020.

BONIFACIO, Eduardo S. Manutenção 4.0 - Os aspectos da quarta revolução industrial sob a perspectiva da manutenção, 2017. Disponível em:

$<$ https://wellelaser.com/manutencao-4-0-os-aspectos-da-quarta-revolucao-industrial-sob-aperspectiva-da-manutencao/>. Acesso em 30 mai. 2020.

CNI. Nota Técnica do Ministério do Trabalho esclarece o uso de "Robos Colaborativos" frente à NR12, 2018. Disponível em:

<https://conexaotrabalho.portaldaindustria.com.br/media/publication/files/RT\%20Informa\%2 0N.\%2021\%20outubro\%20$\% 20$ Nota $\% 20$ Tecnica $\% 20$ do\%20Ministerio\%20do\%20Trabalho\%20esclarece\%20o\%20uso \% 20de $\% 20$ Robos $\% 20$ Colaborativos $\% 20$ frente $\% 20 \mathrm{a} \% 20 \mathrm{NR} \% 2012$.pdf $>$. Acesso em 01 jun. 2020. 
CNI. RELAÇÕES TRABALHISTAS NO CONTEXTO DA INDÚSTRIA 4.0, 2017.

Disponível em:

<https://conexaotrabalho.portaldaindustria.com.br/media/publication/files/Relacoes_trabalhist as_web.pdf $>$. Acesso em 08 jun. 2020.

CORTIZO, Teófilo Moreira Neto. A HISTÓRIA DA EVOLUÇÃO DO SISTEMA DE GESTÃO DE MANUTENÇÃO, 2017. Disponível em:

$<$ https://www.webartigos.com/artigos/a-historia-da-evolucao-do-sistema-de-gestao-demanutencao/75650>. Acesso em 30 mai. 2020.

FIA. Indústria 4.0: o que é, consequências, impactos positivos e negativos, 2018.

Disponível em: <https://fia.com.br/blog/industria-4-0/>. Acesso em 18 mai. 2020.

GLOBO. Comissão aprova relatório da MP da liberdade econômica, 2019. Disponível em: <https://globoplay.globo.com/v/7759130/>. Acesso em 29 mai. 2020.

GOLDBACH, Claudio H. A Manutenção é a porta de entrada da Indústria 4.0?, 2019. Disponível em: <https://www.industria40.ind.br/artigo/17646-a-manutencao-e-a-porta-deentrada-da-industria-40>. Acesso em 25 abr. 2020.

IEDI. Indústria 4.0: Desafios e Oportunidades para o Brasil, 2017. Disponível em: <https://www.iedi.org.br/cartas/carta_iedi_n_797.html>. Acesso em 20 mai. 2020.

IMBRAEP. História Segurança do Trabalho, 2017. Disponível em:

$<$ https://inbraep.com.br/publicacoes/historia-seguranca-do-trabalho/>. Acesso em 08 jun. 2020.

LEVANDOSKI, Michel. Manutenção na Indústria 4.0, 2018. Disponível em: $<$ https://qualityway.wordpress.com/2018/05/24/manutencao-na-industria-4-0-por-michellevandoski/>. Acesso em 29 abr. 2020.

MARKETING. Acidentes de trabalho: o que a indústria 4.0 pode fazer?, 2018. Disponível em: <https://sigga.com.br/blog/acidentes-de-trabalho/>. Acesso em 15 abr. 2020.

MARTINS, Túlio. Evolução da Manutenção em 4 Fases, 2019. Disponivel em: <https://tuliomartins.com.br/evolucao-da-manutencao/>. Acesso em 30 mai. 2020.

MAXINST. Manutenção industrial 4.0: o que é e quais os benefícios para sua empresa, 2020. Disponível em: <https://www.revistamanutencao.com.br/literatura/tecnica/tecnologiada-informacao/manutencao-industral-4-0-o-que-e-e-quais-os-beneficios-para-suaempresa.html>. Acesso em 25 mai. 2020.

NASCIF, Júlio e KARDEC, Alan. Manutenção como Função Estratégica: 5 ed. Rio de Janeiro: Qualitymark, 2019.

NEVES, Daniel e SOUSA, Rafaela. Revolução Industrial, 2020. Disponível em: $<$ https://brasilescola.uol.com.br/historiag/revolucao-industrial.htm>. Acesso em 29 mai. 2020. 
NORMANDO, Juliana. Indústria 4.0 na prática: Manutenção Industrial, 2018. Disponível em: 〈http://www.senaiempresa.ms.senai.br/industria-4-0-na-pratica-manutencao-industrial/>. Acesso em 30 mai. 2020.

PILZ. Revisão da norma de segurança ISO para robôs industriais, 2018. Disponível em: <https://www.pilz.com/pt-BR/company/news/articles/196225>. Acesso em 01 jun. 2020.

SAKURAI, Ruudi. "AS REVOLUÇÕES INDUSTRIAIS ATÉ A INDUSTRIA 4.0." Interface Tecnologica, 2018, p.480-489.

SÃO FRANCISCO, Portal. Segunda Revolução Industrial: consequiências sociais, 2015. Disponível em: <https://www.portalsaofrancisco.com.br/historia-do-brasil/segundarevolucao-industrial $>$. Acesso em 17 abr. 2020.

SIMONETTI, Rogério M. Altera a redação da Norma Regulamentadora no 12 Segurança no Trabalho em Máquinas e Equipamentos, 2019. Disponível em: <http://www.trabalho.gov.br/images/NRs/portaria-n-916-nr-12-anexos.pdf>. Acesso em 05 jun. 2020.

SOGGI. A Revolução Industrial: marco da evolução da Saúde e Segurança dos Trabalhadores, 2019. Disponível em: <https://sogi.com.br/blog/saude-e-segurancaocupacional-sso/>. Acesso em 16 mai. 2020.

SOUSA, Rafaela. Segunda Revolução Industrial, 2019. Disponível em: <https://brasilescola.uol.com.br/historiag/segunda-revolucao-industrial.htm>. Acesso em 16 mai. 2020.

TELES, Jhonata. O Planejamento e Controle da Manutenção na Indústria 4.0, 2017. Disponível em: <https://engeteles.com.br/pcm-na-industria-4-0/>. Acesso em 20 abr. 2020.

VENTURELLII, Márcio. MANUTENÇÃO 4.0, 2019. Disponível em: <https://marcioventurelli.com/2019/05/16/manutencao-4-0/>. Acesso em 30 mai. 2020.

XAVIER, Renato. O que é possível esperar da gestão da SST na Indústria 4.0?, 2019. Disponível em: <https://blog.cestanobre.com.br/o-que-e-possivel-esperar-da-gestao-da-sst-naindustria-4-0-entenda/>. Acesso em 15 abr. 2020. 